\title{
The effects of repeated idea elaboration on unconscious plagiarism
}

\author{
Louisa-Jayne Stark and Timothy J. Perfect \\ University of Plymouth, Plymouth, England
}

\begin{abstract}
Unconscious plagiarism occurs in a recall task when someone presents someone else's idea as his or her own. Recent research has shown that the likelihood of such an error is inflated if the idea is improved during the retention interval, but not if it is imagined. Here, we explore the effects of repeating the elaboration phase during the retention interval. Participants in a group first generated alternate uses to common objects before elaborating the ideas either by imagining them or by improving them. This elaboration phase occurred once, twice, or not at all. Later, they attempted to recall their original ideas and generate new ideas. Repeated imagery did not inflate unconscious plagiarism on either task. In contrast, repeating the improvement phase increased plagiarism to dramatically high levels in the recall task. The latter effect might be particularly pertinent to real-world cases of plagiarism in which the ideas under dispute have been the subject of creative development over many occasions.
\end{abstract}

In everyday life, individuals are continuously exposed to information from a host of different sources, such as friends, family, and the media. Often, remembering the precise source of information is not important, but on occasion it can be crucial. For instance, when someone is engaged in a creative pursuit, it is important for copyright purposes that they recall the source of prior information to prevent its being incorrectly presented as new. Working life often involves problem solving approached collaboratively with colleagues, but problems may arise later when the ownership of an idea that has been generated is in dispute (Carroll \& Perfect, 2002). There have been both anecdotal accounts and legal cases in which the original sources of ideas have been disputed and individuals have been acknowledged to have unconsciously plagiarized earlier works (Taylor, 1965). In the present work, we seek to determine the factors that may lead to such errors when people attempt to remember the source of an idea.

Brown and Murphy (1989) developed an experimental paradigm to examine the psychological mechanisms through which unintentional plagiarism occurs. The overwhelming body of subsequent research has utilized this three-phase paradigm. Initially, in the generation phase, a group of 4 participants took turns producing category exemplars (e.g., fruits), trying not to repeat any response given by another participant. At test, the participants attempted to recall their ideas without producing any idea generated by another group member (the recall-own phase) and then generated further new ideas, making sure that they did not repeat any previously given answer (the generatenew phase). Unconscious plagiarism was observed in all the tasks, with the highest rates in the recall-own and the generate-new tasks (7\%-14\%; Brown \& Murphy, 1989).
Unconscious plagiarism has since been obtained using a wide variety of materials and procedures, and various factors have been shown to alter the rate of plagiarism. For instance, using real categories during generation elicits more plagiarism than does using fictitious ones (Brédart, Lampinen, \& Defeldre, 2003; Brown \& Murphy, 1989; Macrae, Bodenhausen, \& Calvini, 1999; Tenpenny, Keriazakos, Lew, \& Phelan, 1998). Similarly, orthographic categories produce more plagiarism than semantic categories (Brown \& Murphy, 1989). Imposing a retention interval between generation and testing also increases the likelihood of such errors (e.g., Brown \& Halliday, 1991; Marsh \& Bower, 1993). Plagiarism has also been detected across a range of more creative tasks, such as finding solutions to word puzzles (Marsh \& Bower, 1993; Marsh \& Landau, 1995), brainstorming ideas to solve problems (Landau, Marsh, \& Parsons, 2000; Marsh, Landau, \& Hicks, 1997), generating alternate uses of common items (Stark \& Perfect, 2006; Stark, Perfect, \& Newstead, 2005), and drawing novel space creatures (Marsh, Landau, \& Hicks, 1996). Plagiarism has been shown for both auditory and visual materials (Brown \& Murphy, 1989; Marsh \& Bower, 1993) and has been demonstrated when participants are tested individually (e.g., Marsh \& Landau, 1995), in dyads (e.g., Brédart et al., 2003), or in groups of four or more (e.g., Brown \& Murphy, 1989; Stark \& Perfect, 2006). Thus, basic demonstrations of unconscious plagiarism using the three-phase paradigm are clear, consistent, and generalizable.

Recently, we introduced into the paradigm an additional stage following generation, on the basis that real-world cases of unconscious plagiarism may involve extended contemplation of an idea after initial idea exposure (Stark et al., 2005; see also Perfect \& Stark, in press; Stark \& Per- 
fect, 2006, 2007). It is possible that this may influence the sense of idea ownership, and so we examined the impact of different ways of thinking about ideas during the retention interval. The procedure required that participants first generate solutions to the Alternate Uses Test (Christensen, Guilford, Merrifield, \& Wilson, 1960) in groups of four. For example, the participants took turns generating novel uses for a brick. Following generation, the participants thought about these ideas in different ways. For one quarter of the ideas, the participants generated three ways of improving the idea (the generative-elaboration condition). For another quarter of the ideas, the participants imagined the idea (the imagery-elaboration condition). The remaining ideas were split evenly between those that were heard again and those not re-presented. One week later, testing followed the standard paradigm with both recallown and generate-new tests. Two aspects of the findings were noteworthy. First, there was a dissociation between plagiarism in the generate-new and recall-own tasks. Both kinds of elaboration reduced plagiarism in the generatenew task, relative to baseline. However, in the recall-own task, plagiarism increased following generative elaboration, but not following imagery elaboration. In a series of follow-up studies, we have replicated this basic pattern (Stark \& Perfect, 2006, 2007).

Stark et al. (2005) explained this pattern using a sourcemonitoring account (Johnson, Hashtroudi, \& Lindsay, 1993). We argued that during the recall-own phase, participants use qualitative attributes of items in memory to make attributions about the likely source of an idea that comes to mind. Ideas that are initially generated are likely to contain codes associated with the process of generation. Conversely, those ideas that were heard being generated by others will likely contain more perceptual records. The elaboration phase also creates memories with differing qualitative characteristics. Imagining an idea will create perceptual qualities that become associated with the idea, whereas generating improvements will create records of generative processing of the improvements that become associated with the idea itself. Consequently, when memory is searched for ideas originally generated, imagined ideas are less likely to be produced, since they contain no records of generative processing. However, those ideas that were improved are more likely to resemble ideas originally generated, since both contain records of generation, and so are plagiarized.

Whereas Stark et al. (2005) were originally motivated by a desire to understand the impact of different forms of thinking about ideas during the interval, studies to date have looked only at the impact of a single session of idea elaboration, carried out soon after idea exposure. However, in the real world, when an individual creates something he or she thinks is new, such as a song, a novel, or an academic paper, a great deal of time and effort is invested, and the finished product is rarely completed during a single session. Rather, ideas are developed in an ongoing process in which repeated efforts are invested into the formulation of the finished product. This invested effort may serve to increase confidence that the idea is owned by the individual, thereby increasing source-monitoring errors. Consequently, in the present work, we explore the effects of repeated elaboration on subsequent judgments of the ownership of ideas.

There is a second purpose to the manipulation of the number of elaboration phases. In the previous work, imagination has had no reliable impact upon the rates of plagiarism in the recall-own phase. Although we have argued that this is not because imagery is a weak manipulation of memory strength, it remains the case that we are drawing inferences from the null hypothesis (Stark \& Perfect, 2006, 2007; Stark et al., 2005). Consequently, a second opportunity to form an image of the idea should result in even stronger memories than does a single-imagery session. This should be revealed in higher levels of correct recall for twice-imagined ideas than for once-imagined ideas. The key question of interest, then, is whether this higher memory strength translates into more unconscious plagiarism in either the recall-own or the generate-new test phase. To explore this question, the present study contrasts conditions involving a single-imagery phase with one in which ideas were imagined on two separate occasions. If the previous lack of plagiarism following imagery was due to the relatively weak effect of our imagination manipulation, we might legitimately expect to see greater plagiarism when the imagery phase is repeated. Conversely, if it is the qualitative nature of the imagery manipulation that is key, as we have argued previously, the number of repetitions of the imagery phase should have no impact upon the likelihood of plagiarism.

A second possible reason for the lack of an imagery effect in our previous studies is that the form of elaboration (imagery or idea improvement) was manipulated within subjects. If idea improvement is a particularly powerful means of producing plagiarism, improved ideas may prevent imagined ideas from being output at test. This follows because participants tried to recall the four ideas they originally generated: If they succeeded in correctly recalling two or three and plagiarized one improved idea, there may be little or no scope to demonstrate plagiarism for the imagined ideas. Consequently, in the present work, we manipulated the nature of the elaboration (idea improvement or imagery) in a between-subjects design. If idea improvement has previously been suppressing plagiarism of the imagined ideas, imagery should show higher levels of plagiarism than does control with this design.

In order to explore the effects of repeated imagery on subsequent unconscious plagiarism, the participants initially generated ideas as a group, before imagining some of those ideas on one or two separate occasions. Their subsequent performance on recall-own and generate-new phases was contrasted with that of participants in a second condition, who generated ideas in the same manner but improved ideas on one or two occasions during the retention interval. Because all previous studies of idea elaboration have used a single test phase, this study will therefore allow us to test whether the high levels of plagiarism following idea improvement reported previously represent a ceiling level of plagiarism or whether further idea improvement can create even higher levels of plagiarism. 


\section{METHOD}

\section{Participants}

Sixty-four students participated in the generation phase. However, 9 participants failed to attend the second testing session, and so only 55 participants completed the experiment. The participants were undergraduates from the University of Plymouth and received either partial fulfillment of a course requirement or $£ 8$ for their participation in this study.

\section{Design}

A 2 (elaboration: improvement or imagery) $\times 4$ (time of elaboration: control, Day 1 only, Day 3 only, or both Day 1 and Day 3) mixed design was utilized, with repeated measures on the second factor.

\section{Procedure}

The participants were randomly allocated to one of the elaboration conditions (idea improvement or idea imagery). The procedure for both conditions was identical, except for the form of elaboration used. The participants were initially tested in groups of 4 , and each participant was randomly assigned a seat around a table. In the generation phase, the participants were informed that they would be given an object name and that their task was to think of nontraditional, nonconventional uses for that object. As an example, they were given the object name newspaper and were told that a possible use for the newspaper could be to make a paper hat. During the experiment proper, the participants generated uses for the following objects: brick, button, paperclip, and shoe (Alternate Uses Test; Christensen et al., 1960). The participants were given the first object name and were asked to give their uses one by one when instructed to by the experimenter. Once all the participants had given their first idea, the group was instructed to give a second idea and so on, in a different random order for each set of 4 ideas. Each participant gave a total of four uses for each object; thus, 64 ideas were generated in total across objects.

The elaboration phase that followed was conducted over two sessions. The first session immediately followed the idea generation phase, and the second session was conducted 3 days later. All the participants engaged in both elaboration sessions, although which items they elaborated on each occasion was manipulated as described below. Elaboration instructions were manipulated between subjects. The participants in the imagery condition were instructed to rate all the ideas presented to them during the elaboration phase, using two 5-point rating scales: how easy the ideas were to imagine $(1=$ difficult to imagine, $5=$ easy to imagine $)$ and how effective they thought the ideas would be $(1=$ not effective, $5=$ very effective). The participants in the idea improvement condition were instructed to write down three ways to improve each idea that was presented. For example, if the idea was use a newspaper to make a hat, possible improvements they might write down could be to paint it, to waterproof it, and to attach a flower. Because the participants wrote these responses, they never encountered the improvements suggested by others and so could not be influenced by them.

Figure 1 illustrates how ideas were elaborated at different times during the retention interval. The set of ideas generated by a group was split into four sets of 16 ideas, with 1 idea from each participant for each object in each of the sets. One set of ideas was not re-presented at all during the retention interval and, so, constituted control ideas. A second set was re-presented only on Day 1, and the participants were asked to elaborate those ideas, using either imagery or improvement, as appropriate. A third set of ideas was re-presented only on Day 3, and these ideas were treated in the same manner as were those presented on Day 1. A final set of ideas was re-presented on both Day 1 and Day 3, intermingled with the ideas presented only once. On Day 1, all ideas were being re-presented for the first time, and so all ideas were subject to the same process of elaboration. However, on Day 3, the participants saw ideas represented for the first time, together with ideas that they had elaborated on Day 1. They were instructed that if they could recall their previous elaboration, they should write that down; otherwise, they should produce a new response.

The recall-own and generate-new testing phases were identical for both elaboration conditions and were completed on Day 7, 1 week after the initial generation phase (4 days after the second elaboration phase). The participants returned to complete the recall-own and generate-new phases in their original groups. In the recall-own phase, the participants were shown the four category headings (i.e., brick, paperclip, shoe, and button) that they had previously generated to in the first session, with four blank spaces under each for their written responses. The categories were displayed in a different random order for each participant. The participants were instructed to try to recall all of their own ideas from the first session, up to four ideas per object. For the generate-new phase, the participants were
Phase Session Control
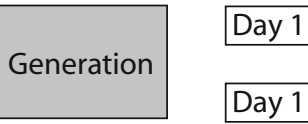

Day 1
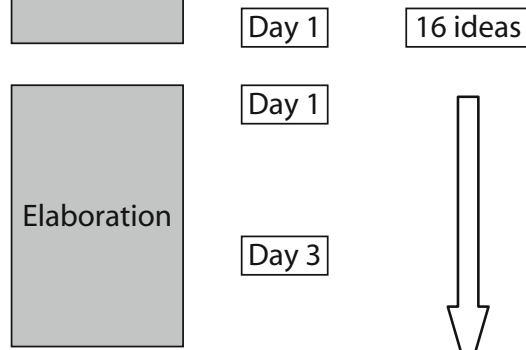

Test

\section{Condition}

$\begin{array}{cc}\begin{array}{c}\text { Elaborate } \\ \text { once }\end{array} & \begin{array}{c}\text { Elaborate } \\ \text { once } \\ \text { (Day 1) }\end{array} \\ \text { (Day 3) }\end{array}$

Generate 64 ideas
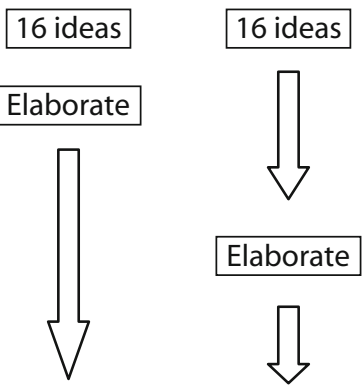

16 ideas

Elaborate

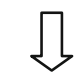

Elaborate

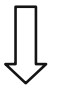

\section{Elaborate \\ twice \\ (Days 1 \& 3)}

Recall-Own
Generate-New

Figure 1. A schematic representation of the procedure, illustrating how items were allocated to elaboration phases (imagery or improvement). 
given the same headings in a new random order and were asked to write down four novel uses for the objects, avoiding answers that had been given during the first session. The test session lasted approximately $20 \mathrm{~min}$.

\section{RESULTS}

During the initial generation phase, there were no repetitions of previous responses (i.e., zero plagiarism errors). This contrasts with a number of previous studies (e.g., Brown \& Murphy, 1989; Marsh \& Bower, 1993), in which participants repeated responses given earlier in the generation phase. However, the initial tasks in the previous studies were ones in which the number of potential responses was quite constrained (i.e., generating members of categories such as fruit or generating words starting with be), and so the likelihood of duplication was considerable. There are two reasons why the Alternate Uses Test does not produce such duplications. First, the number of potential answers is less constrained, and so the likelihood of unintentional duplication is reduced. Second, the responses given by each participant are much more distinctive and, so, memorable enough for the participants to avoid duplication. In our previous studies using the same generation tasks, we have also found minimal levels of initial plagiarism during the generation phase, although we did not previously report this (Stark \& Perfect, 2006; Stark et al., 2005).

Because of the structure of the design, a word of explanation is required about how the data from the final test phases were scored. Although the participants responded to the original object cues, the data were scored in response to elaboration status (control, Day 1, Day 3, or both). This means that although recall could not exceed four ideas per object, there could be more than four kinds of responses associated with a particular elaboration condition. This is not intuitively obvious, and so we will begin by clarifying how this pattern might occur.

For the purposes of this illustration, imagine that elaborating an idea increases the likelihood of correct recall, whereas elaborating an idea twice increases the rate of unconscious plagiarism. Now consider a participant trying to recall the ideas that he or she originally generated to the memory cue brick. In reality, 1 of the 4 ideas was never elaborated (control), 2 were elaborated once (on Day 1 or 3 ), and 1 was elaborated twice. The participant is likely to recall the 3 ideas that he or she elaborated. However, rather than correctly recalling the control idea, he or she may intrude with someone else's idea that he or she subsequently elaborated twice; that is, he or she may plagiarize. If the same occurs with the other object cues, this hypothetical participant will have correctly recalled 12 of the ideas that he or she originally generated, but additionally, he or she will have erred by intruding 4 twiceelaborated ideas.

Now consider breaking these 16 recall attempts down by elaboration status. For the twice-elaborated ideas, the participant has correctly recalled all four of his or her own ideas but has plagiarized another four ideas. So, even when recall is limited to four responses to a cue, it is possible for recall of items from a particular elaboration status to exceed this limit. Indeed, this is exactly what the participants did in this experiment, as we shall see.

What this illustration also clarifies is that the likelihood of producing one kind of response is not independent of the likelihood of producing another. Since the total number of responses elicited from participants is fixed at a maximum of 16 , it follows that if they do succeed in correctly recalling their 16 ideas, they cannot plagiarize. Similarly, if they intrude twice-improved ideas, this may reduce the propensity to intrude once-elaborated ideas. We will return to this issue in the Discussion section.

In the recall-own phase, we did not force the participants to generate four responses to each category cue, but for the generate-new phase, the participants were required to generate four new ideas per category. All the participants met this requirement. The overall numbers of ideas correctly recalled and the rates of plagiarism in the recallown and generate-new phases are summarized in Table 1. This clearly demonstrates that the nature of the elaboration had little effect on the ability of the participants to recall their own ideas or to generate new ones. However, the two forms of elaboration had dramatically different impacts upon the likelihood of the participants' plagiarizing when they were attempting to recall their own ideas. Ideas improved twice were plagiarized over 13 times more often than control ideas.

\section{Correct Recall}

The participants were instructed to recall the ideas that they had originally generated for each object. The top row of Table 1 shows the effects of elaboration on the number of ideas the participants recalled that they had previously generated.

A 2 (elaboration type: improvement or imagery) $\times 4$ (elaboration time: control, Day 1, Day 3, or Day 1 and Day 3) mixed ANOVA on correct recall showed a significant main effect of elaboration status $[F(3,162)=31.1$, $\left.M S_{\mathrm{e}}=27.6, p<.001\right]$. Multiple pairwise comparisons, with a Sidak-adjusted alpha level of .05 , revealed that ideas that were elaborated twice (Days 1 and 3) were recalled more often than any of the other ideas. Recall of ideas that were elaborated on Day 1 or 3 did not differ from each other, but both demonstrated improved recall, relative to control. There was a significant main effect of elaboration type $\left[F(1,54)=8.58, M S_{\mathrm{e}}=16.59, p<.05\right]$, so that more ideas were correctly recalled following the imagery elaboration condition. However, there was no significant interaction between elaboration type and elaboration time $\left[F(3,162)=1.70, M S_{\mathrm{e}}=2.66, p=.17\right]$.

\section{Unconscious Plagiarism}

Recall-own task. Ideas that were recalled by a participant that had been generated by another participant during the generation phase were scored as unconsciously plagiarized ideas. These were subject to a 2 (elaboration type: generative or imagery) $\times 4$ (elaboration time: control, Day 1 only, Day 3 only, or Day 1 and Day 3) mixed ANOVA that revealed a significant main effect of elaboration time $\left[F(3,162)=25.25, M S_{\mathrm{e}}=25.25, p<.001\right]$. 
Table 1

Mean Rates of Correct Recall and Plagiarism Within the Recall-Own

and Generate-New Phases for Control Ideas and Ideas That Were Subject to

Imagery or Improvement Once (Day 1 or 3) or Twice (Days 1 and 3)

\begin{tabular}{|c|c|c|c|c|c|c|c|c|}
\hline \multirow[b]{3}{*}{ Task } & \multicolumn{8}{|c|}{ Elaboration Status } \\
\hline & \multicolumn{2}{|c|}{ Control } & \multicolumn{2}{|c|}{$\begin{array}{c}\text { Elaboration on } \\
\text { Day } 1\end{array}$} & \multicolumn{2}{|c|}{$\begin{array}{c}\text { Elaboration on } \\
\text { Day } 3\end{array}$} & \multicolumn{2}{|c|}{$\begin{array}{c}\text { Elaboration on } \\
\text { Days } 1 \text { and } 3\end{array}$} \\
\hline & $\begin{array}{c}M \\
\text { (of } 4 \text { ) }\end{array}$ & $S D$ & $\begin{array}{c}M \\
\text { (of } 4 \text { ) }\end{array}$ & $S D$ & $\begin{array}{c}M \\
\text { (of } 4 \text { ) }\end{array}$ & $S D$ & $\begin{array}{c}M \\
\text { (of 4) }\end{array}$ & $S D$ \\
\hline \multicolumn{9}{|l|}{ Imagery Elaboration } \\
\hline Recall & 1.80 & 0.86 & 2.86 & 0.92 & 2.83 & 1.07 & 3.10 & 0.86 \\
\hline Recall-own plagiarism & 0.21 & 0.41 & 0.41 & 0.68 & 0.55 & 0.83 & 0.59 & 0.98 \\
\hline$\%$ & 10.4 & & 12.5 & & 16.3 & & 16.0 & \\
\hline Generate-new plagiarism & 0.41 & 0.68 & 0.55 & 0.95 & 0.59 & 0.73 & 0.28 & 0.59 \\
\hline$\%$ & 10.3 & & 13.8 & & 14.8 & & 7.0 & \\
\hline \multicolumn{9}{|l|}{ Generative Elaboration } \\
\hline Recall & 1.0 & 1.04 & 2.15 & 1.40 & 2.22 & 1.31 & 3.04 & 0.90 \\
\hline Recall-own plagiarism & 0.19 & 0.93 & 0.81 & 0.41 & 0.78 & 0.56 & 2.81 & 0.59 \\
\hline$\%$ & 16.0 & & 27.3 & & 26.0 & & 48.0 & \\
\hline Generate-new plagiarism & 0.70 & 0.82 & 0.56 & 0.85 & 0.26 & 0.60 & 0.52 & 0.75 \\
\hline$\%$ & 17.5 & & 14.0 & & 17.5 & & 13.0 & \\
\hline
\end{tabular}

Note- $\%$, percentage of responses output that were plagiarized. For recall, this is dependent on the number of items recalled, whereas for generate new, it is out of 4 responses.

The means are displayed in the second row of Table 1. There was a significant main effect of elaboration type $\left[F(1,54)=15.48, M S_{\mathrm{e}}=28.07, p<.001\right]$, and crucially, there was a significant interaction between elaboration type and time for the ideas plagiarized in the recall-own phase $\left[F(3,162)=16.30, M S_{\mathrm{e}}=0.91, p<.001\right]$. This interaction was followed up with tests of simple main effects for each form of elaboration. Imagery elaboration had no effect on unconscious plagiarism rates $[F(3,52)=1.06$, $p<.37$. In contrast, idea improvement did impact upon the rate of plagiarism $[F(3,52)=19.7, p<.001]$. Pairwise comparisons with a Sidak-adjusted alpha level of .05 indicated that none of the imagery elaboration conditions differed. In contrast, all the conditions in the generative elaboration condition differed, with the exception of the Day 1 and Day 3 elaboration conditions. Table 1 shows just how dramatic the increase in plagiarism rates was in the idea improvement condition. In absolute terms, the participants were over 13 times more likely to produce a plagiarized idea in the twice-elaborated condition than to plagiarize a control idea. Even expressed as a proportion of ideas output, the participants' plagiarism was 3 times as high for twice-improved ideas (48\% of ideas recalled were plagiarized), as compared with control (16\% of ideas output were plagiarized).

One potential explanation for this improvement effect is that these ideas became more readily confused because the improvements that the participants gave to those ideas were shared across ideas that came from different sources. For instance, a person may "improve" several ideas by suggesting that the object is decorated. Some of these ideas may be theirs, and some may be from other group members. Subsequently, the participant may recall the improvement of decoration but confuse which idea this improvement was associated with and, consequently, plagiarize an idea. In order to test this potential explanation, we looked in more detail at the nature of the improvements in the idea improvement conditions, ignoring differences between the Day 1, Day 3, and both Day 1 and Day 3 conditions. ${ }^{1}$ For each idea, each of the three improvements given by a participant was checked against all the other improvements that had been provided by that participant during the experiment. This checking was conducted only within each participant's set of ideas because the participants were never aware of the improvements given by others and, so, could not plagiarize each other's improvements. If an improvement to an idea was repeated elsewhere during the improvement phase, this was counted as a repetition, regardless of how often that improvement was repeated. For example, consider the idea of using a brick as a doorstop. This idea could be improved by adding a cork base, sculpting it into a decorative shape, and painting it. If the improvements of adding a cork base and sculpting into a decorative shape were unique, whereas the improvement of painting was found to be associated with three other ideas, we would rate the idea of using a brick as a doorstop as having one shared improvement.

The outcome of this process was that each idea that was improved was coded as sharing no improvements with any other ideas, sharing one improvement with other ideas, sharing two improvements, or sharing three improvements. Note that multiple improvements were not necessarily shared with another single idea but could have been distributed over several ideas. Table 2 shows the number of improvements that were shared for ideas that were subsequently plagiarized or not. Our reasoning was that if duplication of improvements leads to plagiarism, the ideas associated with unique improvements should be less likely to be plagiarized later, whereas those ideas sharing improvements should be plagiarized more often. In fact, the likelihood of subsequent plagiarism was unrelated to the number of improvements shared across ideas $\left[\chi^{2}(3)=0.84, p=.85\right]$.

Generate-new task. The participants were required to generate four new ideas per category cue, but often the 
Table 2

Proportions of All Ideas and Plagiarized Ideas That Shared Improvements With Other Ideas

\begin{tabular}{lcccc}
\hline & \multicolumn{4}{c}{$\begin{array}{c}\text { Number of Shared Idea } \\
\text { Improvements }\end{array}$} \\
\cline { 2 - 5 } & 0 & 1 & 2 & 3 \\
\hline All ideas & .34 & .35 & .24 & .07 \\
Plagiarized ideas & .32 & .39 & .23 & .07 \\
\hline
\end{tabular}

participants unconsciously plagiarized another person's ideas or inadvertently duplicated one of their own previous ideas (self-plagiarism). Ideas were counted as an instance of plagiarism only once.

A 2 (elaboration type) $\times 4$ (elaboration time) mixed ANOVA was conducted on number of plagiarized ideas in the generate-new phase. This revealed no main effects of elaboration time $\left[F(3,162)=0.80, M S_{\mathrm{e}}=0.41, p=.5\right]$ or elaboration status $\left[F(1,54)=0.20, M S_{\mathrm{e}}=0.15, p=\right.$ $.65]$ and no interaction between the two $[F(3,163)=2.19$, $\left.M S_{\mathrm{e}}=1.11, p=.09\right]$. Thus, in contrast to the recall-own plagiarism, there was no evidence of a reliable impact of elaboration on the likelihood of a subsequent plagiarism error in the generate-new task. No follow-up tests were conducted.

\section{DISCUSSION}

The most striking finding in this study was the extraordinarily high rates of plagiarism in the recall-own phase following repeated generative elaboration, relative to repeated imagery elaboration. There are several ways of expressing the magnitude of this effect. In absolute terms, improving an idea twice led to over 13 times as many plagiarized ideas relative to control, 5.8 times as many as once-imagined ideas, 4.8 times as many as twiceimagined ideas, and 3.5 times as many as once-improved ideas. One can also express the rates of plagiarism relative to the number of ideas recalled. That is, one can ask what proportion of ideas that participants claim as their own are plagiarized. For the imagery elaboration condition, $10 \%$ of the control ideas recalled were plagiarized, $13 \%$ of the ideas imagined on Day 1, 16\% of the ideas imagined on Day 3 , and $16 \%$ of the ideas imagined twice. The equivalent figures for the idea improvement condition were $16 \%$ (control), 27\% (Day 1), 26\% (Day 3), and 48\% (both). Thus, following two sessions of improvement, almost half the ideas that the participants claimed as their own, were, in fact, someone else's. This is an extremely high rate of plagiarism that exceeds the levels of plagiarism obtained following one session of generative elaboration either in the present study or in previous studies (Stark \& Perfect, 2006; Stark et al., 2005).

The very high level of plagiarism seen in the twiceimproved condition in the present work is noteworthy in a number of respects. What makes this rate of plagiarism particularly compelling is that the ideas that were plagiarized were highly distinctive. Recall that in the initial generation phase, no idea duplication occurred. This indicates that the generation task was sufficiently open-ended that the likelihood of accidental duplication was negligible and that the ideas that were generated were sufficiently memorable to allow them to be rejected as old should they come to mind. Even 1 week later, when the participants attempted to generate new ideas, the ideas were sufficiently memorable to restrict the plagiarism rate to $13 \%$ for twice-improved ideas. Thus, twice-improved ideas were not duplicated at encoding, were relatively infrequently plagiarized during the generate-new task, but were very often plagiarized during recall.

This pattern is not found elsewhere in the literature. Outside our own previous work, only one previous article has reported recall-own plagiarism rates over $40 \%$. Landau and Marsh (1997) reported two experiments, each with two conditions, using the Boggle task at encoding. Recall-own plagiarism rates ranged from $42 \%$ to $56 \%$, thus matching the high levels of plagiarism found here. However, at test, the participants in those experiments were required to provide four responses for the recallown task, inflating the likelihood of guessing, whereas the present study used free report, thus minimizing guessing and so reducing the likelihood of obtaining plagiarism errors. At encoding, the participants in Landau and Marsh's study were likely to duplicate an earlier response (rates ranged from $13 \%$ to $18 \%$ ), but such errors did not occur here at all. For the generate-new task, the rates of plagiarism in Landau and Marsh's experiments ranged from $34 \%$ to $42 \%$, but only from $7 \%$ to $18 \%$ in the present data. The strong implication from the pattern of data reported by Landau and Marsh is that their participants did not have a very clear memory for the original solutions, and so a substantial proportion of the recall-own plagiarism may have been due to accidental duplication, rather than idea appropriation. Unfortunately, there is no baseline condition against which we can estimate the likelihood of accidental duplication in Landau and Marsh's study. However, in the present study, the control condition served just such a function. If we assume that all the plagiarism errors in the control condition were due to such accidental duplication, which is the most cautious assumption, it is still clear that idea improvement substantially increases plagiarism.

Comparison of the two single-improvement conditions raises an interesting issue: The participants were just as likely to plagiarize ideas that were improved soon after they had initially been presented as to plagiarize those that were improved 3 days later. From a temporal discrimination perspective, one might have anticipated that the later elaboration phase could be more easily segregated from the original generation phase in memory. Consequently, one might have expected the participants to be able to discount the later elaboration phase more easily and, hence, make fewer plagiarism errors. However, clearly, this was not the case. One potential explanation is that the participants took part in all phases and were quite poor at determining which ideas were processed during each phase. Perhaps a between-subjects manipulation of the timing of the elaboration phase might be a useful way to test this idea.

In contrast to the effects of idea improvement on unconscious plagiarism, repeated idea imagery did not result in 
an increase in recall-own intrusions, relative to the ideas that were elaborated only once or relative to control ideas. Thus, the present data replicate those previously obtained with a within-subjects design in which participants engaged in both forms of elaboration. In the present study, the participants engaged in only one form of elaboration during the retention interval, but the same pattern of findings pertain. Thus, the repeated lack of an idea imagery effect on recall-own plagiarism does not appear to have been due to suppression from recall of improved ideas. The absence of an idea imagery effect does not appear to have occurred because the imagery manipulation was ineffective: Imagining an idea twice reliably increased the number of ideas correctly recalled, relative to control ideas. Indeed, correct recall following imagery elaboration was higher than that following idea improvement. What was unexpected was that this extended to performance in the control condition.

We believe that the higher control performance in the imagery condition is an indirect result of the high levels of plagiarism in the improvement condition. Recall that the participants were invited to remember their four ideas for each of the four category cues. The data indicate that the participants were likely to correctly recall the elaborated ideas. They were also almost as likely to plagiarize the ideas that were improved twice. Thus, for a person in the generative elaboration condition, they are likely to report the twice-improved ideas, whatever their source. Given that the total number of responses requested was 4, this leaves fewer spaces to fill with ideas that were elaborated once or not at all. Consequently, the presence of plagiarized ideas in the output suppresses the likelihood of correctly reporting an item, both directly, in the sense that only 4 responses were requested, and indirectly, in the sense that output interference from earlier recalled items reduced the likelihood of recall of subsequent items (Tulving \& Hastie, 1972). Across all categories, the generative elaboration condition produced an average of 4.59 plagiarized items (out of 16 possible responses), whereas the imagery elaboration condition produced 1.76 . The difference (2.83) equates to a difference of 0.71 items per elaboration status, which corresponds almost exactly to the difference between the two elaboration conditions for control items.

There are two corollaries of this argument. One is that plagiarized items in the generative elaboration condition are output in priority to weaker items that the participants originated but did not elaborate. This implies that plagiarized items are not merely guesses added toward the end of the retrieval phase. A second point to note, which reinforces both this argument and the magnitude of the plagiarism effect, is that we used free report, not forced. For instance, Marsh and Bower (1993) forced participants to output four items, and the highest reported plagiarism rates across three experiments was $32 \%$. The majority of these items were reported as guesses and so, presumably, would have been withheld in a free-report situation. In comparison, in our study, the participants were free to withhold responses that they were unsure of and still plagiarized $48 \%$ of the time they reported a twice-improved idea. This, coupled with our earlier arguments about the likelihood of accidental duplication in previous studies, reinforces the power of the present data.

This powerful effect in the recall-own data stands in contrast to the null effects seen in the generate-new task. Neither form of elaboration, whether carried out once or twice, influenced the likelihood that a plagiarized idea would be produced when an attempt was made to generate a novel use for an object. The timing of the single elaboration phase also failed to influence the rate of plagiarism in the generate-new task. In this respect, these data closely follow the pattern reported in our previous work, but the lack of main effects on the generate-new task in the present study are clearly worthy of some scrutiny.

Clearly, we must acknowledge at the outset that discussing null effects is always problematic. There may be many reasons for the failure to detect an effect, including, most obviously, a lack of power. However, the fact that we have repeatedly failed to find an impact of elaboration on generate-new plagiarism, although, at the same time, always finding an effect of improvement on recall-own plagiarism gives us greater belief in the veracity of the finding. It is the contrast between the three measures of correct recall, recall-own plagiarism, and generate-new plagiarism that is so compelling.

Previous accounts of plagiarism in the generate-new phase have been built around the concept of memory strength. Old ideas that have raised activation but have failed to reach a recall threshold are likely to be accidentally output in a generation task (Marsh \& Landau, 1995). On the other hand, ideas with a very high level of activation are likely to be recalled. Consequently, there is an optimal level of activation that should show the highest level of plagiarism. The difficulty with such a strength account is that it is not clear what the optimal level of activation is. If one starts with the assumption that control ideas are suitably activated for plagiarism to occur, one would expect elaborated ideas to show less plagiarism, since they would be too active to plagiarize. Instead, they should be recalled as old. Indeed, the data do show that elaborating ideas improves recall. But contrary to a simple strength account, elaborating does not correspondingly reduce generate-new plagiarism. Similarly, if one starts with the assumption that elaborated ideas are suitably active to be plagiarized, control ideas should be plagiarized less often, because they are insufficiently active. However, they are not. In fact, the flat rate of plagiarism errors in the generate-new task, coupled with a dramatic rise in correct recall following elaboration, is hard to integrate into a simple strength account.

We favor a source-monitoring account of the present data. The starting point for this account is a consideration of the demands of the two retrieval tasks. For the generatenew task, participants attempt to avoid the repetition of old ideas, and so any form of elaboration which increases memory distinctiveness is likely to help participants reject old ideas that come to mind. However, for the recall-own task, participants are faced with a different problem, for which the cue of memory strength is not as informative. Their task is to recall ideas that they originally generated, 
avoiding ideas generated by others, some of which they have thought about during the retention interval. In line with Johnson et al.'s (1993) source-monitoring framework, we believe that participants may focus on the qualitative characteristics of ideas to judge their source. In particular, the participant's own ideas should be associated with records of the cognitive operations of having initially generated the ideas. However, participants are also required to generate improvements to ideas during the retention interval, and so, for some ideas that were generated by others, there are associated records of cognitive operations concerned with generation. If participants confuse the process of idea generation with the process of improvement generation, they are likely to plagiarize.

Finally, we wish to consider the implications of the present data for plagiarism in the real world. Our original rationale for introducing an elaboration phase into the standard three-stage paradigm was that real-world plagiarism is unlikely to follow a single exposure to an idea. To that end, we began our exploration of the effects of idea imaging and idea improvement on subsequent plagiarism rates. The present study is the first to explore the effects of repeating that elaboration phase, and the result has been the highest level of plagiarism that we have yet observed. Although further research is necessary to establish the generality of the effect, the clear implication is that further phases of idea elaboration and improvement, over even longer retention intervals, are likely to further increase the rate of plagiarism.

It is not difficult to see how disputes between colleagues about the ownership of ideas might occur. Imagine two scientists working on a grant proposal. In an initial meeting, each generates many ideas for potential studies that might be included. However, between this initial meeting and the subsequent finished grant proposal, they are likely to meet and discuss the ideas often. Between meetings, each of them is likely to reflect on the ideas generated, attempting to refine and, so, improve the ideas. Many months later, when they discuss who should be the principal applicant or who should be the first author on the paper, it is easy to see how each may see himself or herself to be the senior partner. The process of elaboration that each of them has engaged in has led both to believe that he or she was the originator of the initial ideas.

When discussing these ideas with colleagues, it has often been put to us that science is a process of building upon the ideas of others and that this is not generally regarded as plagiarism. Even as preeminent a scientist as Isaac Newton acknowledged that he stood on the shoulders of giants. Could it not be argued similarly that our participants are not plagiarizing but recalling modified ideas as their own in an appropriate fashion? We believe not, for two reasons. First, our experimental instructions were very clear and were understood by all the participants. Their task was to recall the original ideas generated, and that is what they did. Unfortunately, they tended to recall someone else's original ideas. They did not recall the elaborated ideas. Our second argument is that the modifications did not alter the fundamental nature of the idea. Using a paperclip as a guitar pick constitutes an original idea. Bending the paperclip, filing it down, and coating it in plastic might make it a bet- ter guitar pick, but does not alter the fundamental idea of using a paperclip as a guitar pick. The person who came up with the improvements cannot legitimately claim ownership of that idea. Famous legal cases, such as that involving George Harrison, revolve around exactly this point. His song "My Sweet Lord" was not exactly the same as The Chiffons' "He's So Fine," but it was sufficiently similar as to be judged to be fundamentally the same, and so his prosecution was successful.

In 1997, Landau and Marsh gave the following advice to writers wishing to avoid plagiarism:

Rather than disrupt the creative process, a writer might benefit from scrutinizing the source of each idea upon completion of a piece of work. In this way, the creative process could proceed unimpeded, and the writer could later apply the more stringent type of decision processes that are used by participants during the recall-own task in order to avoid plagiarizing information. (p. 270)

Clearly, given the present data, our advice would be rather different. Where other people's ideas have been worked on and improved, the likelihood of a plagiarism error during recall is high and is made higher by repetition of the improvement phase. Previously, we have shown that this propensity to plagiarize improved ideas survives financial inducement to avoid plagiarism (Stark et al., 2005), and more recently, we have shown that the same pattern is seen in a source-monitoring task (Stark \& Perfect, 2007). Thus, we seriously doubt whether a source memory judgment after a prolonged period of idea development is likely to succeed in detecting which ideas are one's own and which are plagiarized. Our advice is therefore simple: Don't fall out with colleagues over the source of ideas on the basis of your memory. Where extended idea improvement has occurred, you have nearly a $50 \%$ chance of being wrong.

\section{AUTHOR NOTE}

This work was funded by the Economic and Social Research Council in the form of a studentship award to the first author and a subsequent project grant to both authors (R000221647). Correspondence concerning this article should be addressed to T. J. Perfect, School of Psychology, University of Plymouth, Plymouth PL4 8AA, England (e-mail: tperfect@plymouth.ac.uk).

\section{REFERENCES}

Brédart, S., Lampinen, J. M., \& Defeldre, A. C. (2003). Phenomenal characteristics of cryptomnesia. Memory, 11, 1-11.

Brown, A. S., \& Halliday, H. E. (1991). Cryptomnesia and source memory difficulties. American Journal of Psychology, 104, 475-490.

Brown, A. S., \& Murphy, D. R. (1989). Cryptomnesia: Delineating unconscious plagiarism. Bulletin of the Psychonomic Society, 25, 327.

Carroll, M. A. V., \& Perfect, T. J. (2002). Unconscious plagiarism. In T. J. Perfect \& B. Schwartz (Eds.), Applied metacognition (pp. 146-168). Cambridge: Cambridge University Press.

Christensen, P., Guilford, J., Merrifield, R., \& Wilson, R. (1960). Alternate Uses Test. Beverly Hills, CA: Sheridan Psychological Service.

Johnson, M. K., Hashtroudi, S., \& Lindsay, D. S. (1993). Source monitoring. Psychological Bulletin, 114, 3-28.

LAndau, J. D., \& Marsh, R. L. (1997). Monitoring source in an unconscious plagiarism paradigm. Psychonomic Bulletin \& Review, 4, 265-270. 
Landau, J. D., Marsh, R. L., \& Parsons, T. E. (2000). Dissociation of two kinds of source attributions. American Journal of Psychology, 113, 539-551.

Macrae, C. N., Bodenhausen, G. V., \& Calvini, G. (1999). Contexts of cryptomnesia: May the source be with you. Social Cognition, 17, 273-297.

MARSH, R. L., \& Bower, G. H. (1993). Eliciting cryptomnesia: Unconscious plagiarism in a puzzle task. Journal of Experimental Psychology: Learning, Memory, \& Cognition, 19, 673-688.

MarSh, R. L., \& LANDAU, J. D. (1995). Item availability in cryptomnesia: Assessing its role in two paradigms of unconscious plagiarism. Journal of Experimental Psychology: Learning, Memory, \& Cognition, 21, 1568-1582.

Marsh, R. L., Landau, J. D., \& Hicks, J. L. (1996). How examples may (and may not) constrain creativity. Memory \& Cognition, 24, 669-680.

Marsh, R. L., LANDAU, J. D., \& Hicks, J. L. (1997). Contributions of inadequate source monitoring to unconscious plagiarism during idea generation. Journal of Experimental Psychology: Learning, Memory, \& Cognition, 23, 886-897.

Perfect, T. J., \& Stark, L.-J. (in press). Tales from the Crypt . . o omnesia. In J. Dunlosky \& R. Bjork (Eds.), A handbook of memory and metamemory. Mahwah, NJ: Erlbaum.
Stark, L.-J., \& Perfect, T. J. (2006). Elaboration inflation: How your ideas become mine. Applied Cognitive Psychology, 20, 641-648.

Stark, L.-J., \& Perfect, T. J. (2007). Whose idea was that? Source monitoring for idea ownership following elaboration. Memory, 15, 776-783.

Stark, L.-J., Perfect, T. J., \& Newstead, S. (2005). When elaboration leads to appropriation: Unconscious plagiarism in a creative task. Memory, 13, 561- 573.

TAYLOR, F. K. (1965). Cryptomnesia and plagiarism. British Journal of Psychiatry, 111, 1111-1118.

Tenpenny, P. L., Keriazakos, M. S., Lew, G. S., \& Phelan, T. P. (1998). In search of inadvertent plagiarism. American Journal of Psychology, 111, 529-559.

Tulving, E., \& Hastie, R. (1972). Inhibition effects of intralist repetition. Journal of Experimental Psychology, 92, 297-304.

\section{NOTE}

1. For 2 participants, the improvements for 1 of 2 days were not available, and so this analysis is based on only 25 participants.

(Manuscript received January 9, 2007; revision accepted for publication May 14, 2007.) 